\title{
Representation of Older Latinxs in Cohort Studies at the Rush Alzheimer's Disease Center
}

\author{
David X. Marquez ${ }^{a, b}$ Crystal M. Glover ${ }^{a, c}$ Melissa Lamar ${ }^{a, c}$ Sue E. Leurgans ${ }^{a, d}$ \\ Raj C. Shaha, e Lisa L. Barnes ${ }^{a, d}$ Neelum T. Aggarwal ${ }^{a, d}$ Aron S. Buchman ${ }^{a}$ \\ David A. Bennett ${ }^{a}$ \\ ${ }^{a}$ Rush Alzheimer's Disease Center, Chicago, IL, USA; ${ }^{b}$ Department of Kinesiology and Nutrition, University of Illinois \\ at Chicago, Chicago, IL, USA; 'Department of Psychiatry and Behavioral Sciences, Rush Medical College, Chicago,

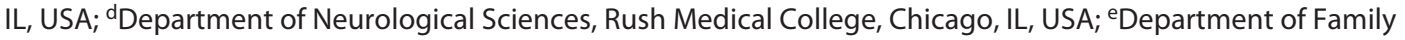 \\ Medicine, Rush Medical College, Chicago, IL, USA
}

\section{Keywords \\ Latinx $\cdot$ Alzheimer's disease $\cdot$ Health disparities $\cdot$ Cognition}

teristics of non-Latinx blacks and non-Latinx whites. Finally, we outline challenges and considerations as well as potential next steps in cognitive aging research with older Latinxs.

(c) 2020 S. Karger AG, Basel

\section{Introduction}

Conservative estimates indicate that Alzheimer's disease and related dementias (ADRD) currently affects 5.8 million Americans, with a projected increase to 14 million by 2050 [1]. Among Latinxs in the USA, the number diagnosed with ADRD is expected to grow by $>800 \%-$ from nearly 400,000 in 2012 to approximately 3.5 million by 2060 [2]. Compared to older non-Latinx whites, older Latinxs have a higher risk and prevalence of ADRD - partially attributed to their longer life spans and the presence of adverse, albeit modifiable, risk factors such as obesity, metabolic syndrome, type 2 diabetes mellitus, and other cardiovascular conditions [3]. However, our understanding of the disproportionate ADRD burden among older Latinxs remains incomplete.

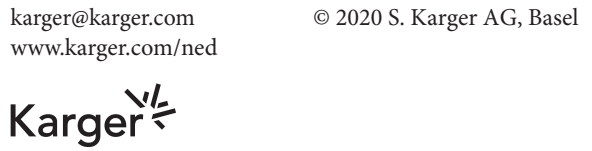


It is important to identify potential causes and related risk reduction strategies specific to this vulnerable population. We cannot assume that findings from ADRD studies, primarily with older non-Latinx whites, will apply to other races and ethnicities. For example, several traditional risk factors for cognitive decline and Alzheimer's dementia in older non-Latinx whites do not demonstrate the same level of risk in older Latinxs, including apolipoprotein $\varepsilon 4$ status [4]. Older Latinxs face potentially distinctive risk factors for ADRD such as structural assimilation [5] and might have potential resilience factors like familial and other relationships, and religiosity or spirituality. Given that previous research has shown those factors to be associated with healthy aging [6] and cognition [7], a greater understanding of their role in ADRD among older Latinxs is warranted. Furthermore, studies explicitly focused on older Latinxs can characterize the diversity among older Latinxs in relation to ADRD and address an urgent public health need [8].

Researchers across the USA have contributed significantly to the field of Latinx health and aging and continue to build evidence in this area (Table 1). For example, longitudinal studies of diverse populations have included non-demented Latinxs along with non-Latinx blacks and whites to examine stroke and related risk factors [9-11], as well as aging and incident dementia $[9,12-15]$. Research has also focused on blood biomarkers of older Latinxs from select countries of origin with and without a diagnosis of mild cognitive impairment (MCI) or Alzheimer's dementia [4, 16-20]. Other targeted studies of older Latinxs have incorporated a small cadre of cognitive measures in a larger framework [4, 21, 22-24]. These and other studies [25-31] have contributed significantly to the field of Latinx health and aging.

Even with these studies, many questions remain regarding aging and ADRD in the Latinx community. One major gap in our understanding of cognitive aging and ADRD among older Latinxs pertains to the dearth of brain tissue from older Latinxs, especially from persons without dementia. Notably, a key feature of aging and ADRD research includes the requirement or option of organ donation upon death for a more complete understanding of $\mathrm{ADRD}$, from etiology to potential prevention and treatment. Brain autopsies and resultant examinations of brain tissue from decedents of diverse ethnic and racial backgrounds are essential for generalizability, for representation, and for improvement of ADRD treatment and care for all individuals affected by the disease [32]. Few studies with older Latinxs request organ donation from study participants upon death, and despite per- sistent efforts to increase the participation of older Latinxs in ADRD research, the amount of available brain tissue from Latinxs is limited [33].

Through 5 cohort studies, the Rush Alzheimer's Disease Center (RADC) [8-10] aims to conceptualize and conduct needed studies of older adults across diverse racial and ethnic groups. The foundation for partnering with older Latinxs, in particular, began with our earliest cohort study, the Religious Orders Study (ROS) [34]. Within ROS, we recruit and maintain Latinxs (among other races/ethnicities) who are Roman Catholic clergy without dementia, all of whom must agree to an annual clinical evaluation and organ donation upon death. Overall, ROS participants have high levels of education. Subsequently, through the Rush Memory and Aging Project (MAP) [35], we constructed the infrastructure for community-based outreach and recruitment coupled with community/home-based testing. MAP participation requires consenting to organ donation and most participants reside in Continuing Care Retirement Communities and other group residence sites. However, Latinxs, non-Latinx blacks, and non-Latinx whites of lower socioeconomic status tend to reside in individual homes throughout the greater Chicago area, and may be missed by these recruitment efforts. Although ROS/MAP remains productive in understanding correlates of Alzheimer's dementia and cognitive health in aging, ROS/ MAP participants are largely non-Latinx whites (88.8\%), in no small part due to the requirement for organ donation as a condition of study enrollment. In 2004, the RADC extended its efforts to address cognitive aging in older non-Latinx blacks with the introduction of the Minority Aging Research Study (MARS) and later the RADC African American Core (AACORE), both with a sole focus on community-dwelling non-Latinx blacks $[36,37]$. Both MARS and AACORE recruit for brain donation as an optional component of the studies. From this foundation, we initiated a focused cohort study of Latinxs through the RADC, named the Latino Core. Like MARS and AACORE, participants are community-dwelling and organ donation is optional. Currently, all 5 cohorts (i.e., ROS, MAP, MARS, AACORE, and Latino Core) maintain a harmonized battery of tests, including assessments of many risk factors and cognitive and motor testing. The harmonization of data collection within the RADC addresses recent recommendations to establish a collaborative infrastructure across existing cohorts that include diverse racial and ethnic groups in an effort to address research gaps in the area [8]. Furthermore, the RADC is poised to identify whether or how baseline characteristics 


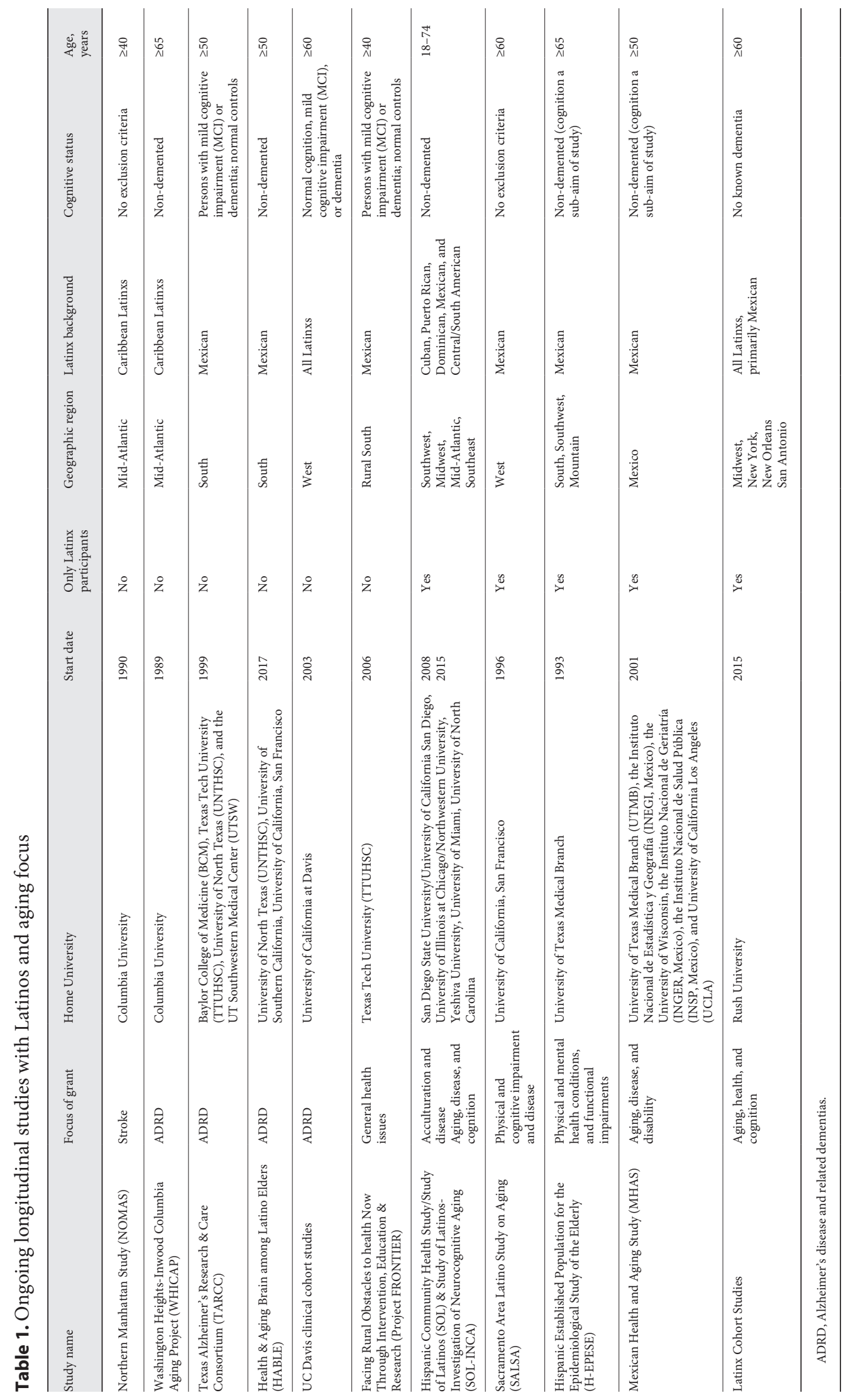


overlap or differ based on the unique personal, cultural, and historical contexts of older Latinxs - exclusively or in comparison to older non-Latinx black and/or older nonLatinx whites.

Through its 5 cohort studies, the RADC collects data and biospecimens including brain donation from community-based, urban, non-demented, diverse older Latinxs to examine the transition from normal aging to MCI to the earliest stages of dementia. The overall aim of the paper is to provide information from the RADC, so that researchers can learn from our participants and procedures to better advance the science of ADRD in Latinxs. The specific aims of this paper are to: (1) outline the harmonized study design across the 5 RADC cohort studies, especially ROS, MAP, and the Latino Core, all of which include a detailed assessment of risk factors for Alzheimer's dementia in older Latinxs without known dementia at baseline; (2) describe the annual clinical evaluation and our approach to discussing organ donation at time of death; (3) demonstrate the baseline characteristics of Latinxs, non-Latinx whites, and non-Latinx blacks across all 5 harmonized RADC cohort studies; and (4) provide suggestions for others doing such work, including future directions in conducting research in the Latinx community.

\section{Methods/Design}

\section{Participants}

Inclusion criteria for research participation among older Latinxs in RADC cohort studies include self-identification as Latinx, no known dementia diagnosis, and agreeing to an annual clinical evaluation and the donation of antemortem biospecimens. We aim for Latinxs aged 65 years and older. ROS, MAP, AACORE, and MARS do not have a Latinx requirement, but there are additional criteria. The Latino Core aims to maintain a panel of approximately 300 older Latinxs without dementia at baseline. The RADC and its cohort studies are based in Chicago, Illinois, and study recruitment takes place across the greater Chicago metropolitan area, except ROS, which recruits throughout the USA. With over 2 million Latinx residents, the greater Chicago metropolitan area [38] has among the highest number of Latinxs in the USA, with great diversity among Latinx residents [38]. Thus, the RADC is an ideal location for longitudinal studies of cognitive aging in older Latinxs. All 5 studies were approved by the Institutional Review Board of Rush University Medical Center. All participants provide informed consent and those who agree to brain donation also sign the Uniform Anatomical Gift Act (AGA).

\section{Procedures}

RADC recruitment efforts across all cohort studies, including those focusing on older Latinxs, are conducted by the same team of staff members, with race/ethnicity-matched recruitment occurring most times. Recruitment efforts (non-probabilistic sampling) are similar across studies, in that presentations are conducted in various locations. ROS recruitment is primarily in convents and monasteries and MAP is primarily in CCRC sites. Before the Latino Core, Latinx recruitment was the same in ROS as for non-Latinx whites and African Americans, and the same as in MAP, except that in both studies agreement to organ donation is required at the time of enrollment. With the onset of Latino Core, there was explicit allocation of resources to recruiting Spanish-speaking Latinxs. Importantly, our staff for recruitment and testing are bilingual in Spanish and English, and bicultural, but they are part of 2 different teams: those involved in outreach and education with the ORE Core and research assistants, respectively. Building trust with organizations has been essential. By starting small and building our networks in the Latinx community, we have gained the trust and respect of organizations. Presentations include staff engagement with, and presentations at, community-based locations, where older Latinxs and their loved ones may visit including senior centers, community centers, churches, parks, health centers and clinics, senior housing facilities, senior fairs and health fairs, and consulates (e.g., the Mexican Consulate in Chicago, located less than a half mile from Rush University Medical Center). Additionally, our team has benefitted from interviews and stories of our work with our local CBS station, the Chicago Tribune, and our local Univision station. These stories, especially those in Spanish, have expanded our outreach in the Latinx community in the Chicago area. We outline additional harmonized methods and procedures below.

Measures Available in All 5 RADC Cohort Studies (ROS, MAP, MARS, AACORE, and Latino Core)

The 5 RADC cohort studies utilize an extensive harmonized clinical evaluation interview and battery of neuropsychological tests. Research assistants collect data across several cohort studies. Those who are bilingual collect all data for the Latino Core. The complete clinical evaluation and battery of tests, including blood draws, take approximately $4 \mathrm{~h}$ for the initial baseline assessment; follow-up evaluations are typically shorter. The evaluations are performed by a multidisciplinary team consisting of a research assistant, a psychometrician, a phlebotomist, a research nurse, a neuropsychologist, and an examining clinician. All assessments, across cohorts and race/ethnicity, are conducted in participants' personal residences. Older Latinx participants are tested in their preferred language, English or Spanish, by a data collector fluent in both languages. All assessments are conducted in either English or Spanish consistently throughout the evaluation (i.e., there is no switching between English and Spanish during the assessment). The cognitive test protocol and other measures were translated and back translated about 20 years ago when ROS first started recruiting Latina sisters in San Antonio. Since all 5 cohorts have a large common set of harmonized measures at the item level, we have predictive validity that comes from peer-reviewed manuscript publications. We added some tests at the start of the Latino Core, which are also used in the Hispanic Community Health Study/Study of Latinos (HCHS/ SOL), where US-Spanish translations were validated.

\section{Demographic Characteristics}

All participants report their gender (i.e., male or female), date of birth, and years of education. Age is calculated from birth date to date of the clinical examination. Participants also report their race (e.g., African American/black) and ethnicity (e.g., Hispanic: yes or no) according to the 1990 US Census questions. 
Psychological, Experiential, and Medical Risk Factors

The Big 5 personality factors are assessed with the NEO Personality Inventory [39]. The 10-item form of the Center for Epidemiologic Studies-Depression Scale (CES-D) is used as an ongoing measure of depressive symptoms [40]. Items on a history of a decline in cognition or stroke and the relationship between stroke and cognitive impairment are adapted from the Consortium to Establish a Registry for Alzheimer's Disease (CERAD) [41]; items on a history of parkinsonism and Parkinson's disease (PD) are adapted from DATATOP [42]. Items on a family history of dementia-related illnesses among first-degree relatives follows CERAD [43]. Current prescribed and over-the-counter medications are visually inspected and type, dosage, and frequency are recorded; medications are later coded according to the Drug Products Information Coding System [44-46].

Household and community-level information are summarized to give the county average Duncan Socioeconomic Index (SEI) for head of households, literacy rate in those aged 6 years or older, and proportion of those aged 6-13 years in school, as previously reported [47-49]. For all participants, physical activity is assessed using 5 questions adapted from the 1985 National Health Interview Survey, [50] and social activity is assessed using a 6-item scale that asks how often during the past year participants engaged in common types of activities that involve social interaction [51]. Parent education is the average of years of education of the mother and father.

Cardiovascular disease is assessed with the Rose Questionnaire as employed in the Established Populations for Epidemiologic Studies of the Elderly (EPESE). Sitting and orthostatic blood pressure and pulse are assessed as in the Trials of Hypertension Prevention. The amount and duration of alcohol use are documented with items from the EPESE [52]. Visual acuity is tested with a Snellen card as performed in EPESE and we assess gross auditory function. We document histories of head injury and sequelae using the Brain Injury Screening Questionnaire (BISQ) [53]. BISQ data collection did not start until August 2017, and thus, we present analyses for illustration.

\section{Self-Report Disability}

Self-reported disability status is assessed by participants' rating of their performance of basic activities of daily living (ADL) and self-care functions required for independent living (instrumental activities of daily living, IADL) [54-56]. We also include brief measures of upper and lower extremity physical function, performance, and strength $[57,58]$.

\section{Neurological Examination}

The neurological examination documents the presence of signs representing conditions, other than Alzheimer's dementia, with the potential to impair cognition. Special emphasis is placed on stroke and PD. The neurological examination is as outlined in CERAD [41]. The structured neurological examination incorporates items from the Stroke Data Bank and the National Institutes of Health Stroke Scale $[59,60]$. A modified version of the complete motor section of the Unified Parkinson's Disease Rating Scale (UPDRS) is administered [61, 62]. Neurological examinations are conducted by nurse clinicians following extensive cross-training procedures with board-certified neurologists.

\section{Cognitive Performance Tests}

The cognitive function tests were selected to assess a broad range of cognitive abilities, emphasizing dissociable cognitive tasks that appear to have different anatomic substrates that are commonly affected by Alzheimer's dementia [63-65], including those widely used for clinical classification of persons with possible dementia [41, 66-76]. Tests have been shown to be valid across ethnic and socioeconomic backgrounds and have been validated in Spanish [77, 78]. To date, the RADC uses the same education cutoffs for all cohorts. Tests of episodic memory include Word List Memory (scores of 0-30), Word List Recall (scores of 0-10), and Word List Recognition (scores of 0-10) from the procedures established by the CERAD; immediate and delayed recall of Story A from the Logical Memory subtest of the Wechsler Memory ScaleRevised (scores of 0-25); and immediate and delayed recall of the East Boston Story (scores of 0-12). Tests of semantic memory include Verbal Fluency; the Boston Naming Test (scores of 0-15); and subsets of items from the National Adult Reading Test (scores of $0-10)$. Tests of working memory include the Digit Span subtests (forward and backward; scores of 0-12) of the Wechsler Memory Scale-Revised and Digit Ordering (scores of 0-14). Tests of perceptual speed include the oral version of the Symbol Digit Modalities Test (scores of 0-110), Number Comparison (scores of 0-48), and the Stroop Neuropsychological Screening Test (scores of 0-80). Visuospatial skills with items from Judgment of Line Orientation (scores of 0-15) and Standard Progressive Matrices (scores of 0-16) are also tested. Finally, the Mini-Mental State Examination (MMSE) is used as an overall measure of cognitive abilities (scores of $0-30$ ) [79]. This protocol is portable and administered by trained technicians. The level of function at each evaluation is summarized with composite scores in different cognitive domains, supported by factor analyses across RADC cohorts [80-84]. Composite scores have the advantage of increasing power by reducing random variability and floor and ceiling effects.

Motor, Gait, and Physical Function Performance Tests

Performance evaluations include 11 tests. (1) Grip and (2) pinch strength measured bilaterally using the Jamar ${ }^{\circledR}$ hydraulic hand and pinch dynamometers (Lafayette Instruments, Lafayette) to assess manual strength. Upper extremity dexterity is based on (3) pegs placed in a pegboard (Purdue Pegboard) in $30 \mathrm{~s}$. In addition, (4) participants tap an electronic tapper (Western Psychological Services, Los Angeles, CA, USA) with their index finger as quickly as possible for $10 \mathrm{~s}$. To evaluate gait, participants walk 8 feet and turn $360^{\circ}$ and we measure the $(5+6)$ time and $(7+8)$ number of steps taken on each task. (9) To assess balance, participants stand on each leg for $10 \mathrm{~s}$ and (10) stand on their toes for 10 s. Finally, (11) participants walk an 8-foot line heel to toe and we count the number of steps off line. Ten performance measures, excluding tandem gait, are scaled and averaged to obtain a summary global motor score [85], which has previously been reported to be associated with risk of mortality, incident disability, and incident dementia [86]. Component measures of strength (2 tests), dexterity ( 2 tests), and gait (4 tests) are also formed.

\section{Laboratory Testing}

Blood is drawn at baseline. We have DNA from peripheral blood mononuclear cells or brain tissue. Serum, plasma, and cryopreserved lymphocytes are stored for future studies in secured $-80^{\circ} \mathrm{C}$ freezers and liquid nitrogen tanks equipped with temperature-sensitive alarm systems. Blood is collected in sterile Vacutainer tubes as follows: $16 \mathrm{~mL}$ in serum separator tubes (SSTs), 16 $\mathrm{mL}$ in liquid $\mathrm{K} 3 \mathrm{EDTA}$ tubes, and $16 \mathrm{~mL}$ in cell preparation tubes 
Table 2. Baseline demographic characteristics of participants across RADC cohort studies

\begin{tabular}{|c|c|c|c|c|}
\hline & \multicolumn{4}{|l|}{$\%$ or $\mathrm{M}(\mathrm{SD})$} \\
\hline & \multirow[t]{2}{*}{ Latinx } & \multicolumn{3}{|l|}{ Non-Latinx } \\
\hline & & whites & blacks & other race \\
\hline$N$ & 415 & 3,191 & 1,302 & 30 \\
\hline $\operatorname{Age}^{\mathrm{a}, \mathrm{b}, \mathrm{d}, \mathrm{e}}$ & $72.22(7.66)$ & $79.03(7.45)$ & $73.31(6.75)$ & $77.54(7.69)$ \\
\hline Female $(\%)^{\mathrm{b}, \mathrm{f}}$ & 78.3 & 71.9 & 78.8 & 70.0 \\
\hline Education (years) ${ }^{\mathrm{a}, \mathrm{b}, \mathrm{d}, \mathrm{e}}$ & $11.58(5.34)$ & $16.57(3.55)$ & $14.79(3.43)$ & $15.07(3.39)$ \\
\hline Tested in Spanish (\%) & 58.0 & 0 & 0 & 0 \\
\hline Planned brain donation $(\%)^{\mathrm{b}, \mathrm{d}, \mathrm{f}}$ & 62.8 & 100 & 58.1 & 80.0 \\
\hline
\end{tabular}

Other races include American Indian or Alaska Native, Native Hawaiian, or other Pacific Islander, and Asian. RADC, Rush Alzheimer's Disease Center. ${ }^{\text {a }}$ Difference noted among categories or among ethnic/racial groups on ANOVA $(p<0.01) .{ }^{\mathrm{b}}$ Difference noted between Latinx and non-Latinx whites $(p<0.05) .{ }^{\mathrm{d}}$ Difference noted between Latinx and non-Latinx blacks $(p<0.05)$. ${ }^{\mathrm{e}}$ Difference noted between Latinx and non-Latinx other race $(p<0.05) .{ }^{\mathrm{f}}$ Difference noted among categories or among ethnic/racial groups on $\chi^{2}$ test $(p<0.01)$.

with anticoagulant for cell separation. A centrifuge is brought to all sites for processing of blood, and serum is separated within $1 \mathrm{~h}$ of collection. Serum and plasma are immediately placed in $0.5 \mathrm{~mL}$ aliquots in O-ring sealed cryogenic vials. All specimens are stored until delivery to the RADC laboratory, either in person or by overnight courier, within $24 \mathrm{~h}$ of collection. Routine laboratory results are obtained, reviewed, and shared with the participants.

\section{Diagnostic Classification}

Diagnostic classification proceeds in a multistep data-driven process, as previously described [87]. Clinical diagnoses are made by the examining clinician or by review of a summary of the results when an in-person evaluation is not performed. Classifications include the following: (1) Alzheimer's dementia: the clinical diagnosis of Alzheimer's dementia follows the recommendations of the joint working group of the NINCDS/ADRDA [88]; (2) MCI: the classification of MCI refers to those persons with cognitive impairment who do not meet criteria for dementia [89]; (3) stroke: Diagnostic classification of stroke subtype is made as outlined for the Trial of ORG 10172 in Acute Stroke Treatment (TOAST) based on the medical history and neurologic examination findings [90]. The diagnosis of cognitive impairment related to stroke is consistent with the NINDS/AIREN criteria for vascular dementia except that brain scans are not obtained [91]; (4) PD: a diagnosis of PD is made according to CAPIT criteria [92]; (5) Lewy body diseases: the diagnosis of dementia with Lewy bodies follows the recommendations of the report of the Consortium on Dementia with Lewy Bodies International Workshop [93]; and (6) other conditions: other conditions including delirium, brain tumors, head trauma, and frontotemporal dementia, while less common, follow contemporary standards.

\section{Measures Only Available from Latinx Participants in RADC} Cohort Studies

Acculturation and Cultural Factors

Participants are asked for city and country of birth, with Puerto Rico a separate response from the USA; and how long they have lived in the mainland USA. We record similar information regard- ing participants' parents in the Latino Core, but not ROS or MAP. We also document language preference for data collection.

Acculturation and cultural values (i.e., familism) are assessed with the Short Acculturation Scale for Hispanics (SASH), which documents language- and social-based acculturation levels as well as an overall SASH score [94]. Those authors note that an average of 2.99 is the recommended cut point, for which scores above this point represent higher levels of acculturation and scores below this point represent lower levels of acculturation. The 6-item version of the Sabogal Familism Measure [95] assesses participants' identification/attachment with their family, a key aspect of cultural identity in Latinxs. These measures are also used in the HCHS/ SOL [96].

\section{Data Analysis}

When examining potential crude baseline differences among ethnic/racial groups on categorical variables, $\chi^{2}$ tests were employed in all cases (except for variables on PD for which the Fisher exact tests were used). ANOVAs were employed for examining the same question for continuous variables when assumptions were met, and the Kruskal-Wallis tests were utilized with the remaining variables. Statistically significant $\chi^{2}$ tests were followed by the smaller $\chi^{2}$ tests and/or Fisher exact tests, significant ANOVAs were followed by the Tukey tests, and significant Kruskal-Wallis tests were followed by the Wilcoxon rank sum tests to examine pairwise differences among ethnic/racial groups.

\section{Results}

Baseline characteristics across the RADC cohort studies are shown in Table 2. Enrollment started in 1994 in ROS, 1997 in MAP, and 2015 in Latino Core. Most Latinxs in the RADC cohort studies are from the Latino Core. As of March 2020, Latino Core consists of 218 Latinx participants, ROS has 64 Latinxs of 1,457 participants and 
Table 3. Baseline psychological, experiential, and medical risk factor characteristics of participants across RADC cohort studies

\begin{tabular}{|c|c|c|c|c|}
\hline & Latinx & \multicolumn{3}{|l|}{ Non-Latinx } \\
\hline \multicolumn{5}{|l|}{ Personality (M, SD) } \\
\hline Neuroticism $^{\mathrm{a}-\mathrm{c}}$ & $18.2(5.7)$ & $15.7(6.6)$ & $14.5(6.3)$ & $15.6(5.5)$ \\
\hline Extroversion & $15.2(2.6)$ & $15.5(3.1)$ & $15.6(3.2)$ & $15.6(2.8)$ \\
\hline \multicolumn{5}{|l|}{ Mother } \\
\hline Yes & 20.8 & 21.3 & 20.2 & 8.3 \\
\hline Possible/suspect & 4.0 & 3.8 & 3.4 & 12.5 \\
\hline No & 75.2 & 74.9 & 76.4 & 79.2 \\
\hline \multicolumn{5}{|l|}{ Father } \\
\hline Yes & 7.5 & 11.7 & 9.1 & 0 \\
\hline Past activity ${ }^{\mathrm{b}-\mathrm{d}}$ & $2.5(0.8)$ & $3.0(0.7)$ & $3.1(0.7)$ & $2.8(0.7)$ \\
\hline Resources $^{\mathrm{b}-\mathrm{d}}$ & $6.4(3.7)$ & $10.5(3.0)$ & $9.8(3.1)$ & $9.0(4.9)$ \\
\hline Parental education ${ }^{\mathrm{b}-\mathrm{d}}$ & $6.0(4.2)$ & $9.9(3.5)$ & $8.9(3.6)$ & $8.5(4.6)$ \\
\hline \multicolumn{5}{|l|}{ Physical (M, SD) } \\
\hline Current activity $\mathrm{c}, \mathrm{d}$ & $3.8(4.8)$ & $3.1(3.7)$ & $2.5(4.0)$ & $3.8(4.1)$ \\
\hline \multicolumn{5}{|l|}{ Social (all current) (M, SD) } \\
\hline Social networks ${ }^{\mathrm{d}}$ & $6.5(5.3)$ & $7.6(7.6)$ & $6.3(5.8)$ & $6.9(7.7)$ \\
\hline Social activity ${ }^{\mathrm{b}-\mathrm{d}}$ & $2.5(0.6)$ & $2.6(0.6)$ & $2.7(0.6)$ & $2.6(0.7)$ \\
\hline Social isolation ${ }^{\mathrm{b}-\mathrm{d}}$ & $2.5(0.7)$ & $2.2(0.6)$ & $2.1(0.6)$ & $2.5(0.6)$ \\
\hline Head blow experienced (BISQ) ${ }^{b}$, e $\%$ & 42.4 & 50.1 & 44.4 & 31.5 \\
\hline Hypertension ${ }^{b}, c, e, \%$ & 61.0 & 48.1 & 74.7 & 63.3 \\
\hline $20 / 40$ & 53.1 & 74.0 & 69.9 & 62.5 \\
\hline $20 / 50$ & 21.6 & 12.9 & 14.8 & 16.7 \\
\hline$<20 / 50$ & 25.3 & 13.3 & 15.3 & 20.8 \\
\hline Adequate gross auditory function, $\%$ & 89.0 & 88.9 & 89.9 & 93.8 \\
\hline Smoker (ever) $)^{c, e}, \%$ & 29.1 & 33.1 & 44.9 & 33.3 \\
\hline Smoker (current) $)^{b, c, e}, \%$ & 3.9 & 1.8 & 7.9 & 3.3 \\
\hline Alcohol use ( $\geq 1$ drink/day) $)^{\mathrm{b}, \mathrm{e}}, \%$ & 4.0 & 8.2 & 5.0 & 4.2 \\
\hline Systolic blood pressure ${ }^{\text {a, c }}(\mathrm{M}, \mathrm{SD})$ & $132.3(19.5)$ & $134.1(18.1)$ & $137.9(20.5)$ & $132.6(19.9)$ \\
\hline Diastolic blood pressure $^{\mathrm{a}-\mathrm{c}}(\mathrm{M}, \mathrm{SD})$ & $77.2(11)$ & $74.2(11.0)$ & $80.1(12.1)$ & $76.2(12.2)$ \\
\hline $\mathrm{BMI}^{\mathrm{a}, \mathrm{b}, \mathrm{f}}(\mathrm{M}, \mathrm{SD})$ & $29.6(5.8)$ & $27.3(5.5)$ & $30.2(6.5)$ & $26.3(5.6)$ \\
\hline Serum $(M C G)(M, S D)$ & $3,444.0(1,449.7)$ & $4,915.7(1,608.1)$ & $5,130.6(1,738.4)$ & $4,370.4(1,244.9)$ \\
\hline Plasma (MCG) $(\mathrm{M}, \mathrm{SD})$ & $5,255.8(1,713.9)$ & $5,077.6(1,841.8)$ & $6,369.4(1,652.3)$ & $6,200.0(1,925.7)$ \\
\hline Cryo PBMC (MCG) (M, SD) & $5.6(5.0)$ & $6.4(12.0)$ & $7.5(5.1)$ & $6.3(4.3)$ \\
\hline
\end{tabular}

Other races include American Indian or Alaska Native, Native Hawaiian, or other Pacific Islander, and Asian. RADC, Rush Alzheimer's Disease Center; CES-D, Center for Epidemiologic Studies-Depression Scale; PBMC, peripheral blood mononuclear cell. ${ }^{a}$ Difference noted among categories or among ethnic/racial groups on ANOVA $(p<0.01)$. ${ }^{b}$ Difference noted between Latinx and non-Latinx whites $(p<0.05) .{ }^{c}$ Difference noted between Latinx and non-Latinx blacks $(p<0.05) .{ }^{\mathrm{d}}$ Difference noted among categories or among ethnic/ racial groups on Kruskal-Wallis $(p<0.01)$. ${ }^{\text {e }}$ Difference noted among categories or among ethnic/racial groups on $\chi^{2}$ test $(p<0.01)$. ${ }_{\mathrm{f}}$ Difference noted between Latinx and non-Latinx other race $(p<0.05)$. 
Table 4. Baseline self-report disability of participants across RADC cohort studies

\begin{tabular}{|c|c|c|c|c|}
\hline & \multirow[t]{2}{*}{ Latinx } & \multicolumn{3}{|l|}{ Non-Latinx } \\
\hline & & whites & blacks & other race \\
\hline$N$ & 415 & 3,191 & 1,302 & 30 \\
\hline $\operatorname{Katz~scale}^{\mathrm{c}}(\mathrm{M}, \mathrm{SD})$ & $0.2(0.7)$ & $0.2(0.7)$ & $0.1(0.5)$ & $0.4(1.0)$ \\
\hline Rosow/Breslau scale ${ }^{\mathrm{c}, \mathrm{d}}(\mathrm{M}, \mathrm{SD})$ & $0.5(0.9)$ & $0.7(1.0)$ & $0.7(0.9)$ & $0.9(1.2)$ \\
\hline $\operatorname{IADL~scale}^{\mathrm{c}, \mathrm{d}}(\mathrm{M}, \mathrm{SD})$ & $0.9(1.6)$ & $1.0(1.6)$ & $0.6(1.2)$ & $1.1(1.9)$ \\
\hline Life space ${ }^{c-e}(M, S D)$ & $5.1(1.3)$ & $5.4(1.1)$ & $5.5(0.9)$ & $5.1(1.6)$ \\
\hline Driving $\geq 1 /$ week, $\%$ & 94.7 & 93.6 & 95.0 & 88.9 \\
\hline
\end{tabular}

Other races include American Indian or Alaska Native, Native Hawaiian, or other Pacific Islander, and Asian. RADC, Rush Alzheimer's Disease Center. ${ }^{c}$ Difference noted among categories or among ethnic/racial groups on Kruskal-Wallis $(p<0.01) .{ }^{\mathrm{d}}$ Difference noted between Latinx and non-Latinx whites $(p<0.05)$. ${ }^{\mathrm{e}}$ Difference noted between Latinx and non-Latinx blacks $(p<0.05)$.

MAP has 121 Latinxs of 2,140 participants. Among the 4,938 total RADC participants, $8 \%$ are tested in Spanish. Among the 415 total RADC Latinx participants, $58 \%$ are tested in Spanish, and 77\% of Latino Core participants are tested in Spanish. RADC Latinx participants represent 7 Latin American countries of origin including Colombia, Cuba, Ecuador, Guatemala, Honduras, Mexico, Peru, and the commonwealth of Puerto Rico. In the Latino Core, $56.3 \%$ report being born in Mexico, $16.8 \%$ in Puerto Rico, and $14.3 \%$ in the USA. In MAP, only $7.3 \%$ of all participants report being born outside the USA, the most of which are from Mexico ( 1\%). To date, 69 Latinx participants have died, of whom 66 agreed to organ donation and $48(72.7 \%)$ underwent brain autopsy.

On average, Latinxs were approximately 72 years of age at baseline, with 11 years of formal education. Latinxs were younger at baseline and had fewer years of education compared with non-Latinx blacks and non-Latinx whites. Rates of planned brain donation (i.e., those who signed the AGA divided by the total number of participants by group) of Latinxs were similar to those of non-Latinx blacks, both of which were lower than those in non-Latinx whites (Table 2).

Table 3 shows that Latinxs experience higher levels of neuroticism and depressive symptoms; less social and cognitive activity; and lower parental education than non-Latinx blacks and whites. No differences in a family history of dementia were noted between groups.

Latinxs reported less mobility disability compared with non-Latinx whites (Table 4). Compared with nonLatinx blacks and whites, Latinxs had lower scores on all working memory tests. Compared with non-Latinx blacks and whites, Latinxs had lower scores on most tests of ep- isodic memory, semantic memory, and perceptual speed with the exception of the Stroop on which Latinxs scored better than non-Latinx blacks on word reading and color naming, and better than non-Latinx whites on word reading only (Table 5).

Latinxs had slower walking speeds compared with non-Latinx blacks and non-Latinx whites, and better scores of motor function but lower scores of bradykinesia, Parkinsonian gait, and tremors (Table 6). The 3 groups did not differ in terms of MCI, dementia, or stroke (Table 7). There were significantly fewer Latinxs born in the mainland USA and Latinxs lived in mainland USA for $>40$ years (Table 8). Also, SASH acculturation scores demonstrated that Latinx participants in RADC cohort studies had low levels of acculturation.

\section{Discussion}

The RADC Latino Core, along with Latinxs from ROS and MAP, generates critical resources needed to advance scientific knowledge regarding aging and ADRD among older Latinxs. First, these studies provide annually collected clinical data from older Latinxs free of dementia at baseline for studies of the transition from normal aging to MCI to the earliest stages of dementia. Second, they provide antemortem biospecimens including serum, plasma, genomic DNA, and viable peripheral blood mononuclear cells from older Latinxs to support biomarker studies of aging and ADRD in this population. Third, they provide postmortem brain tissue and neuropathologic data to support studies of the neuropathology and neurobiology of aging and dementia among older 
Table 5. Baseline cognitive test performance of participants across RADC cohort studies

\begin{tabular}{|c|c|c|c|c|}
\hline & \multirow[t]{2}{*}{ Latinx } & \multicolumn{3}{|l|}{ Non-Latinx } \\
\hline & & whites & blacks & other race \\
\hline$N$ & 415 & 3,191 & 1,302 & 30 \\
\hline $\operatorname{MMSE}^{\mathrm{a}, \mathrm{c}, \mathrm{d}}(\mathrm{M}, \mathrm{SD})$ & $27.5(2.9)$ & $27.8(3.0)$ & $27.5(2.8)$ & $26.9(2.3)$ \\
\hline \multicolumn{5}{|l|}{ Episodic memory (M, SD) } \\
\hline Logical memory Ia $a^{a, c}$ & $9.8(4.1)$ & $11.1(4.5)$ & $10.1(2.0)$ & $9.6(3.9)$ \\
\hline Logical memory IIa ${ }^{a, c}$ & $8.3(4.2)$ & $9.4(4.7)$ & $8.4(2.4)$ & $7.5(4.3)$ \\
\hline East Boston Immediate recall ${ }^{\mathrm{a}, \mathrm{c}}$ & $9.2(2.0)$ & $9.5(2.0)$ & $9.2(2.0)$ & $8.6(2.2)$ \\
\hline East Boston Delayed recall ${ }^{\mathrm{a}, \mathrm{c}}$ & $8.7(2.3)$ & $9.0(2.6)$ & $8.7(2.4)$ & $8.8(1.5)$ \\
\hline Word list memory ${ }^{\mathrm{a}, \mathrm{c}, \mathrm{d}}$ & $15.5(4.3)$ & $17.3(4.7)$ & $17.6(4.3)$ & $16.3(4.5)$ \\
\hline Word list recall ${ }^{\mathrm{a}, \mathrm{c}, \mathrm{d}}$ & $4.9(2.2)$ & $5.3(2.5)$ & $5.4(2.3)$ & $5.4(2.5)$ \\
\hline Word list recognition & $9.6(1.2)$ & $9.4(1.5)$ & $9.5(1.3)$ & $9.3(2.0)$ \\
\hline \multicolumn{5}{|l|}{ Semantic memory (M, SD) } \\
\hline Boston naming Test ${ }^{\mathrm{a}, \mathrm{c}, \mathrm{d}}$ & $12.8(2.0)$ & $13.7(1.6)$ & $13.2(2.0)$ & $13.4(1.9)$ \\
\hline Verbal fluency ${ }^{\mathrm{a}, \mathrm{c}}$ & $32.4(8.3)$ & $34.0(10.0)$ & $31.9(8.7)$ & $28.8(9.0)$ \\
\hline Reading test $\mathrm{t}^{\mathrm{a}, \mathrm{c}}$ & $6.0(2.7)$ & $8.2(2.1)$ & $5.8(3.0)$ & $6.9(2.6)$ \\
\hline \multicolumn{5}{|l|}{ Working memory $(\mathrm{M}, \mathrm{SD})$} \\
\hline Digit span forward ${ }^{\mathrm{a}, \mathrm{c}, \mathrm{d}}$ & $6.1(2.3)$ & $8.3(2.0)$ & $8.0(2.0)$ & $6.9(1.8)$ \\
\hline Digit span backward ${ }^{\mathrm{a}, \mathrm{c}, \mathrm{d}}$ & $4.6(1.9)$ & $6.2(2.1)$ & $5.3(2.0)$ & $4.6(1.3)$ \\
\hline Digit ordering $\mathrm{a}, \mathrm{c}, \mathrm{d}$ & $6.2(1.8)$ & $7.2(2.1)$ & $6.5(1.7)$ & $6.4(1.7)$ \\
\hline \multicolumn{5}{|l|}{ Perceptual speed (M, SD) } \\
\hline Symbol digit ${ }^{\mathrm{a}, \mathrm{c}, \mathrm{d}}$ & $32.1(13.4)$ & $38.9(11.6)$ & $35.8(11.9)$ & $32.3(13.0)$ \\
\hline Number comparison $^{\mathrm{a}, \mathrm{c}, \mathrm{d}}$ & $20.6(8.2)$ & $24.9(7.5)$ & $22.9(7.6)$ & $23.1(6.0)$ \\
\hline Stroop word reading a, $\mathrm{d}, \mathrm{e}$ & $51.7(13.1)$ & $50.1(13.3)$ & $47.7(13.6)$ & $42.0(11.2)$ \\
\hline Stroop color naming ${ }^{\mathrm{a}, \mathrm{d}}$ & $18.6(8.0)$ & $18.7(7.7)$ & $16.3(7.8)$ & $17.0(6.4)$ \\
\hline \multicolumn{5}{|l|}{ Visuospatial ability (M, SD) } \\
\hline Line orientation ${ }^{\mathrm{a}, \mathrm{c}}$ & $8.2(3.3)$ & $10.1(3.1)$ & $7.7(3.3)$ & $9.5(3.0)$ \\
\hline Prog matrices ${ }^{\mathrm{a}, \mathrm{c}}$ & $9.9(3.0)$ & $11.3(3.1)$ & $10.1(3.0)$ & $10.1(3.4)$ \\
\hline \multicolumn{5}{|c|}{ Composite measures ( $z$-scores) $(\mathrm{M}, \mathrm{SD})$} \\
\hline Global cognition ${ }^{c, d, f}$ & $-0.1(0.6)$ & $0.9(0.7)$ & $-0.1(0.6)$ & $-0.3(0.5)$ \\
\hline Episodic memory ${ }^{\mathrm{c}, \mathrm{f}}$ & $-0.04(0.7)$ & $0.03(0.8)$ & $0.03(0.7)$ & $-0.15(0.7)$ \\
\hline Semantic memory ${ }^{c, f}$ & $-0.3(0.9)$ & $0.1(0.9)$ & $-0.2(0.9)$ & $-0.3(0.9)$ \\
\hline Working memory ${ }^{c, d} f$ & $-0.6(0.8)$ & $0.1(0.8)$ & $-0.2(0.7)$ & $-0.5(0.6)$ \\
\hline Perceptual speed ${ }^{c, d, f}$ & $-0.5(1.0)$ & $0.1(0.9)$ & $-0.1(0.9)$ & $-0.4(1.0)$ \\
\hline Visuospatial abilityc, $\mathrm{f}$ & $-0.3(0.8)$ & $0.2(0.8)$ & $-0.4(0.8)$ & $-0.2(0.9)$ \\
\hline
\end{tabular}

Other races include American Indian or Alaska Native, Native Hawaiian, or other Pacific Islander, and Asian. RADC, Rush Alzheimer's Disease Center. ${ }^{\text {a }}$ Difference noted among categories or among ethnic/racial groups on Kruskal-Wallis $(p<0.01)$. ${ }^{\mathrm{c}}$ Difference noted between Latinx and non-Latinx whites $(p<0.05) .{ }^{\mathrm{d}}$ Difference noted between Latinx and non-Latinx blacks $(p<0.05)$. ${ }^{\mathrm{e}}$ Difference noted between Latinx and non-Latinx other race $(p<0.05) .{ }^{\mathrm{f}}$ Difference noted among categories or among ethnic/racial groups on ANOVA $(p<0.01)$.

Latinxs. Finally, due to harmonized testing and biospecimen collection across all RADC cohort studies, there are opportunities for comparisons of Latinxs with nonLatinx whites and blacks.

We direct our attention and resources to explicit engagement, recruitment, and retention of older Latinxs through the Latino Core. In combination with ROS and MAP, the number of Latinx participants across RADC cohort studies is approaching a total of 500 participants. Latinxs in RADC cohort studies reported low levels of ac- culturation, similar to those found in the HCHS/SOL cohort [97]. Latinxs also reported higher levels of neuroticism and depressive symptoms compared with nonLatinx blacks and whites. These findings follow previous literature reporting older Latinxs as having a higher odds of screening positive for depression, especially among Latinxs identifying as Mexican, Puerto Rican, or Cuban compared with non-Latinx whites [98]. Elevated levels of neuroticism and depressive symptoms among Latinxs have great importance for brain health as older adults with 
Table 6. Baseline motor performance tests of participants across RADC cohort studies

\begin{tabular}{|c|c|c|c|c|}
\hline & \multirow[t]{2}{*}{ Latinx } & \multicolumn{3}{|l|}{ Non-Latinx } \\
\hline & & whites & blacks & other race \\
\hline$N$ & 415 & 3,191 & 1,302 & 30 \\
\hline \multicolumn{5}{|l|}{ Lower limb function $(\mathrm{M}, \mathrm{SD})$} \\
\hline Walking speed ${ }^{\mathrm{a}, \mathrm{c}, \mathrm{d}}$ & $0.5(0.2)$ & $0.6(0.2)$ & $0.6(0.2)$ & $0.6(0.2)$ \\
\hline Turning speed ${ }^{a, c, d}$ & $0.2(0.1)$ & $0.2(0.1)$ & $0.2(0.1)$ & $0.2(0.1)$ \\
\hline Errors on tandem ${ }^{\mathrm{e}}$ & $1.5(2.0)$ & $1.9(2.6)$ & $1.5(2.1)$ & $1.4(1.8)$ \\
\hline \multicolumn{5}{|l|}{ Upper limb function (M, SD) } \\
\hline Finger tapping & $53.9(9.6)$ & $55.2(8.6)$ & $54.8(8.9)$ & $51.6(9.1)$ \\
\hline Purdue pegboard ${ }^{\mathrm{a}, \mathrm{c}, \mathrm{d}, \mathrm{f}}$ & $11.7(2.3)$ & $10.3(2.5)$ & $11.0(2.5)$ & $9.6(2.6)$ \\
\hline Grip strength ${ }^{\mathrm{a}, \mathrm{c}, \mathrm{d}, \mathrm{f}}$ & $45.5(17.5)$ & $46.9(19.1)$ & $56.1(19.7)$ & $41.9(14.6)$ \\
\hline Pinch strength ${ }^{\mathrm{a}, \mathrm{c}, \mathrm{d}}$ & $12.2(4.5)$ & $11.2(4.9)$ & $13.9(5.3)$ & $9.8(4.6)$ \\
\hline Global motor score $^{\mathrm{a}, \mathrm{d}}(\mathrm{M}, \mathrm{SD})$ & $1.0(0.2)$ & $1.0(0.2)$ & $1.1(0.2)$ & $0.9(0.2)$ \\
\hline \multicolumn{5}{|l|}{ Modified UPDRS score (M, SD) } \\
\hline Total mUPDRS ${ }^{\mathrm{c}-\mathrm{e}}$ & $5.7(7.1)$ & $7.7(7.5)$ & $3.4(4.7)$ & $5.7(6.6)$ \\
\hline Bradykinesia ${ }^{c-e}$ & $8.4(12.0)$ & $10.6(12.0)$ & $5.6(9.7)$ & $5.8(8.6)$ \\
\hline Parkinsonian gait $^{\mathrm{c}-\mathrm{e}}$ & $10.3(13.7)$ & $14.7(15.4)$ & $6.4(10.5)$ & $13.8(16.4)$ \\
\hline Rigidity ${ }^{d, e}$ & $2.2(6.1)$ & $2.9(7.8)$ & $0.7(3.1)$ & $1.7(4.2)$ \\
\hline Tremor $^{\mathrm{c}-\mathrm{e}}$ & $1.7(4.8)$ & $2.7(5.5)$ & $0.6(2.7)$ & $1.7(4.0)$ \\
\hline
\end{tabular}

Other races include American Indian or Alaska Native, Native Hawaiian, or other Pacific Islander, and Asian. RADC, Rush Alzheimer's Disease Center. ${ }^{a}$ Difference noted among categories or among ethnic/racial groups on ANOVA $(p<0.01) .{ }^{c}$ Difference noted between Latinx and non-Latinx whites $(p<0.05) .{ }^{\mathrm{d}}$ Difference noted between Latinx and non-Latinx blacks $(p<0.05) .{ }^{\mathrm{e}}$ Difference noted among categories or among ethnic/racial groups on Kruskal-Wallis $(p<0.01) .{ }^{\mathrm{f}}$ Difference noted between Latinx and Non-Latinx other race $(p<0.05)$.

Table 7. Baseline diagnostic classification of participants across RADC cohort studies

\begin{tabular}{lrrrr}
\hline & \multirow{2}{*}{ Latinx } & \multicolumn{2}{l}{ Non-Latinx } \\
\cline { 3 - 5 } & & whites & blacks & other race \\
\hline$N$ & 415 & 3,191 & 1,302 & 30 \\
Dementia, \% & 4.8 & 5.8 & 4.2 & 6.7 \\
Mild cognitive impairment, \% & 25.1 & 24.0 & 22.5 & 23.3 \\
Stroke, \% & 6.3 & 8.3 & 6.3 & 14.3 \\
Parkinson's disease, $\%$ & 2.6 & 3.0 & 1.1 & 0 \\
\hline
\end{tabular}

Other races include American Indian or Alaska Native, Native Hawaiian, or other Pacific Islander, and Asian. RADC, Rush Alzheimer's Disease Center. ${ }^{\mathrm{b}}$ Difference noted among categories or among ethnic/racial groups on $\chi^{2}$ test $(p<0.01)$.

depression, regardless of ethnicity, have demonstrated a higher rate of progression to Alzheimer's dementia over a relatively short period of follow-up [99]. Relatedly, the current study findings also outline neuropsychological test performance of Latinxs. Latinxs in our studies demonstrated low scores on many such tests. Fewer years of formal education have been noted as a risk factor for the development of ADRD and could be a factor in the baseline scores of the Latinxs from RADC studies. Also, it is possible that Latinx participants have less experience with standardized surveys and tests, which could affect testing at baseline. Over time, we can examine changes in cognition, and control for level of education. Similarly, we will be able to analyze the impact of other factors, such as physical and social activity, and their impact on cognitive scores across race/ethnicity and within Latinxs.

That said, more work is needed to understand and improve cognition among this underserved segment of the US population. One area in further need of study is the potential role of language use and proficiency on test performance. Being bilingual often distinguishes Latinxs from non-Latinx blacks and non-Latinx whites. Toward this end, our team is actively working to develop measures not only of language proficiency, but also patterns of use in our cohort studies involving Latinx participants. Although we do not have that information yet, we are actively pursuing such research at the RADC to determine best practices around both self-reported and objectively assessed proficiency. 
Table 8. Baseline acculturation and cultural factors of participants across RADC cohort studies

\begin{tabular}{|c|c|c|c|c|}
\hline & \multirow[t]{2}{*}{ Latinx } & \multicolumn{3}{|c|}{ Non-Latinx } \\
\hline & & whites & blacks & other race \\
\hline$N$ & 415 & 3,191 & 1,302 & 30 \\
\hline \multicolumn{5}{|l|}{ Country of birth ${ }^{\mathrm{b}}, \%$} \\
\hline $\mathrm{USA}^{\mathrm{d}-\mathrm{f}}$ & 28.5 & 96.5 & 98.6 & 70.4 \\
\hline Colombia & 1.7 & 0.03 & 0 & 0 \\
\hline Costa Rica & 0 & 0.03 & 0 & 0 \\
\hline Cuba & 0.5 & 0 & 0 & 0 \\
\hline Ecuador & 1.5 & 0 & 0 & 0 \\
\hline El Salvador & 0.2 & 0 & 0 & 0 \\
\hline Guatemala & 0.7 & 0 & 0 & 0 \\
\hline Honduras & 1.2 & 0 & 0 & 0 \\
\hline Mexico & 30.0 & 0 & 0 & 0 \\
\hline Peru & 0.7 & 0 & 0 & 0 \\
\hline Puerto Rico & 9.5 & 0 & 0 & 0 \\
\hline Other & 25.4 & 3.5 & 1.4 & 29.6 \\
\hline Years lived in mainland USA $(\mathrm{M}, \mathrm{SD})$ & $42.5(15.6)$ & & & \\
\hline \multicolumn{5}{|l|}{ SASH acculturation $(\mathrm{M}, \mathrm{SD})$} \\
\hline Language & $2.2(1.2)$ & - & - & - \\
\hline Social & $2.4(0.8)$ & - & - & - \\
\hline Total & $2.2(1.0)$ & - & - & - \\
\hline Familism (M, SD) & $21.1(4.6)$ & - & - & - \\
\hline
\end{tabular}

Other races include American Indian or Alaska Native, Native Hawaiian, or other Pacific Islander, and Asian. RADC, Rush Alzheimer's Disease Center; SASH, Short Acculturation Scale for Hispanics. ${ }^{\mathrm{b}}$ Difference noted among categories or among ethnic/racial groups on $\chi^{2}$ test $(p<0.01) .{ }^{\mathrm{d}}$ Difference noted between Latinx and nonLatinx whites $(p<0.05) .{ }^{\mathrm{e}}$ Difference noted between Latinx and non-Latinx blacks $(p<0.05) .{ }^{\mathrm{f}}$ Difference noted between Latinx and non-Latinx other race $(p<0.05)$.

In the future, achieving high rates of follow-up will be critical in studies of cognitive aging and the transition from normal aging to MCI to dementia. RADC staff have substantial experience with the techniques necessary to facilitate follow-up, and they will continue to use these evidence-based strategies, including the following: (1) overcoming barriers to participation by conducting all evaluations in participants' homes; (2) frequent contact with participants including quarterly telephone calls, newsletters, and acknowledgement cards for special occasions; (3) frequent dissemination of research findings, in part, through educational presentations on ADRD and healthy aging in both English and Spanish; and (4) engagement and communication with participants' families. Notably, in the Latino Core, we conduct quarterly "Cafecitos" as retention events in different areas across the Chicago metropolitan area, where groups of participants reside. Currently, Cafecitos consist of small gatherings of approximately 30 participants in which we report study updates, facilitate social networking among participants, and provide a presentation on a topic they are in- terested in (e.g., healthy eating and mental health). Bilingual professionals are solicited to lead these presentations and discussions.

However, challenges exist in recruiting and retaining older Latinxs in research. One challenge to conducting research with older Latinxs involves the intertwined needs for bicultural and/or race/ethnicity-matched staff who are bilingual in English and Spanish - both verbally and written - and continuous outreach efforts. All assessments in RADC cohort studies, including Latino Core, are done in participants' homes/buildings and, at times, require multiple visits per participant, possibly resulting in the need for extended recruitment timelines. However, our experience has indicated that gaining the trust and respect of participants, which requires substantial time investment, is necessary for their recruitment and retention. The increasing polarization of immigrants in the USA highlights the need to establish this trust and respect.

Moreover, gaining the trust of participants' family members is vital, given the collectivist nature of Latinxs. For example, in the consent process, we make sure family 
members are aware of the older adults' interest in the study. Although we do not have direct data yet on how this might have affected recruitment and retention, we assume that the affect has been positive, given the collectivist nature.

Another challenge pertains to RADC cohorts currently consisting of smaller numbers of some Latinx backgrounds (e.g., Cubans) and fewer men than women. We postulate that the smaller numbers of some Latinx backgrounds not only reflect the heterogeneity of Latinxs in the USA but also our primary Chicagoland catchment area, which consists primarily of Latinxs of Mexican and Puerto Rican background. Regarding smaller numbers of men, efforts are being made to learn from our current participants about best approaches to addressing this issue; furthermore, we are specifically targeting men's groups, such as at churches.

Finally, completed brain autopsies present a potential challenge. Overall, we aim to facilitate brain donation in an effort to identify and understand potential Alzheimer's dementia pathways among older adults, especially ethnic and racial minorities. At the RADC, rates of planned brain donation of Latinxs were similar to those of non-Latinx blacks, both of which were lower compared with non-Latinx whites. In an effort to ensure successful brain and organ donation resulting in a completed brain autopsy, we employ the following strategies, all of which are done with participant permission: (1) provide a specific packet to each participant who consents to organ donation (by signing an AGA form, which gives legally binding permission for donation at the time of the donor's death and family members do not have the right to override this decision), and the packet includes flyers and a magnet for his/her refrigerator that gives the RADC telephone number to call upon death, as well as a frequently asked questions document; (2) send information to participants' family members, notifying them of the participants' RADC cohort study involvement and organ donation wishes, and provide them with our telephone number to call upon death; (3) give the lead investigator's business card to participants who have signed the AGA form and strongly encourage them to share it with family members, as the study coordinator will need to be notified at the time of death. After receiving the business card, the family member can call the lead investigator, who can describe the study and emphasize the important role they play in informing us about their loved one's death in an effort to honor participants' brain donation wishes; (4) ask for funeral home information at home visits by the lead investigator and by data collectors at follow-up testing from those who signed the AGA for organ donation;
(5) send letters to funeral homes informing them that a RADC cohort study participant has signed the AGA for organ donation and made arrangements to use their funeral home upon death, so they can call us if they receive notification of the death; and (6) discuss organ donation with those who are not opposed to organ donation but have not signed the AGA for organ donation. These efforts have led to approximately one-third of Latino Core participants signing the AGA.

Despite the strengths of our current work, there are limitations. We lack probabilistic sampling, which could bias comparisons across and within our RADC cohorts. Also, it is possible that there are differences between Latinxs participating in a study in a big Midwest urban area compared to Latinxs from different geographic reasons, countries of origin, and rural settings. Moreover, we have ongoing challenges to obtaining organ donation.

Future work at the RADC focused on Latinx communities will include adding measurements that can help us learn more about brain health in Latinxs via genetic testing and biomarkers [100-107]. We have plans to collect proteomic data and MRI in all Latino Core participants. Our current collection of MRI data from those Latinxs who have signed the AGA for organ donation provides vital data on the brain in vivo that can be combined with other data being collected and described in this paper, including ex vivo autopsy-confirmed neuropathologies related to normal and pathological aging.

Overall, the work at the RADC, especially cohort studies of aging that include older Latinxs, aims to represent older Latinxs in the field of cognitive aging and ADRD. The comprehensive nature of the RADC cohort studies with Latinxs, as seen in Tables 2-8, will allow us to make unique contributions to cohort studies of aging. Adding more Latinx participants to the rich datasets of the RADC cohort studies has several advantages, including the following: ethnic and racial comparisons with non-Latinx whites and blacks due to the harmonization of measures across cohort studies, and within-group comparisons due to the variability of the Latinx participants across RADC cohort studies. Taken together, the data collected can be used to develop risk reduction trials and add to the drug discovery pipeline.

\section{Acknowledgements}

We acknowledge the work of former and current project coordinators, Charlene Gamboa, Teresa Jenkins, Elizabeth Montalvo, Esmeralda Morales, and Tracey Nowakowski. We acknowledge the work of the research assistants and all current and former Out- 
reach and Recruitment Core staff who contribute to the RADC, notably Mauricio Andrade, Elissa Campos, and Yadira Montoya. We also thank the Statistics and Data Management Core of the RADC, including Jennifer Poirier. Most importantly, we acknowledge and thank all participants and their families for their commitment to the study.

\section{Statement of Ethics}

This research complies with internationally accepted standards for research practice and reporting.

\section{Conflicts of Interest Statement}

The authors have no relevant conflicts of interest to declare.

\section{Funding Sources}

The work was supported by grants from the National Institutes of Health (P30AG10161, R01AG17917, RF1AG22018, and R01AG062711).

\section{Author Contributions}

Conception or design of the work (D.X.M., C.M.G., M.L., S.E.L., R.C.S., L.L.B., N.T.A., A.S.B., and D.A.B.); acquisition, analysis or interpretation of data for the work (D.X.M., C.M.G., M.L., S.E.L., and D.A.B.). Drafting the work or revising it critically for important intellectual content (D.X.M., C.M.G., M.L., S.E.L., R.C.S., L.L.B., N.T.A., A.S.B., and D.A.B.). Final approval of the version to be published (D.X.M., C.M.G., M.L., S.E.L., R.C.S., L.L.B., N.T.A., A.S.B., and D.A.B.). Agreement to be accountable for all aspects of the work in ensuring that questions related to the accuracy or integrity of any part of the work are appropriately investigated and resolved (D.X.M., C.M.G., M.L., S.E.L.,R.C.S., L.L.B., N.T.A., A.S.B., and D.A.B.).

\section{References}

1 Alzheimer's Association. 2019 Alzheimer's disease facts and figures. 2019

2 Wu S, Vega WA, Resendez J, Jin H. Latinos and Alzheimer's disease: new numbers behind the crisis. 2016.

3 Chin AL, Negash S, Hamilton R. Diversity and disparity in dementia: the impact of ethnoracial differences in Alzheimer disease. Alzheimer Dis Assoc Disord. 2011;25(3):18795.

4 O'Bryant SE, Johnson L, Reisch J, Edwards M, Hall J, Barber R, et al. Risk factors for mild cognitive impairment among Mexican Americans. Alzheimers Dement. 2013;9(6):622-31. e1.

5 Simpao MP, Espino DV, Palmer RF, Lichtenstein MJ, Hazuda HP. Association between acculturation and structural assimilation and mini-mental state examination-assessed cognitive impairment in older Mexican Americans: findings from the San Antonio Longitudinal Study of Aging. J Am Geriatr Soc. 2005; 53(7):1234-9.

6 Hernandez R, Carnethon M, Giachello AL, Penedo FJ, Wu D, Birnbaum-Weitzman O, et al. Structural social support and cardiovascular disease risk factors in Hispanic/Latino adults with diabetes: results from the Hispanic Community Health Study/Study of Latinos (HCHS/SOL). Ethn Health. 2018; 23(7):1-15.

7 Jung J, Lee CH, Shin K, Roh D, Lee SK, Moon YS, et al. Specific association between religiosity and cognitive functions in Alzheimer's disease. Am J Alzheimers Dis Other Demen. 2019;34(4):254-60.

8 Babulal GM, Quiroz YT, Albensi BC, Arenaza-Urquijo E, Astell AJ, Babiloni C, et al. Perspectives on ethnic and racial disparities in Alzheimer's disease and related dementias: update and areas of immediate need. Alzheimers Dement. 2019;15(2):292-312.

9 Beecham A, Dong C, Wright CB, Dueker N, Brickman AM, Wang L, et al. Genome-wide scan in Hispanics highlights candidate loci for brain white matter hyperintensities. Neurol Genet. 2017;3(5):e185.

10 Gardener H, Wright CB, Dong C, Cheung K, DeRosa J, Nannery M, et al. Ideal cardiovascular health and cognitive aging in the Northern Manhattan Study. J Am Heart Assoc. 2016;5(3):e002731.

11 Caunca MR, Del Brutto V, Gardener H, Shah $\mathrm{N}$, Dequatre-Ponchelle N, Cheung YK, et al. Cerebral microbleeds, vascular risk factors, and magnetic resonance imaging markers: the Northern Manhattan Study. J Am Heart Assoc. 2016;5(9):e003477.

12 Brickman AM, Schupf N, Manly JJ, Luchsinger JA, Andrews H, Tang MX, et al. Brain morphology in older African Americans, Caribbean Hispanics, and whites from northern Manhattan. Arch Neurol. 2008;65(8):105361.

13 Zahodne LB, Manly JJ, Narkhede A, Griffith EY, DeCarli C, Schupf NS, et al. Structural MRI predictors of late-life cognition differ across African Americans, Hispanics, and Whites. Curr Alzheimer Res. 2015;12(7):6329.

14 Schneider BC, Gross AL, Bangen KJ, Skinner JC, Benitez A, Glymour MM, et al. Association of vascular risk factors with cognition in a multiethnic sample. J Gerontol B Psychol Sci Soc Sci. 2015;70(4):532-44.

15 Johnson LA, Gamboa A, Vintimilla R, Edwards $\mathrm{M}$, Hall J, Weiser B, et al. A depressive endophenotype for predicting cognitive de- cline among Mexican American adults and elders. J Alzheimers Dis. 2016;54(1):201-6.

16 Cunningham RL, Singh M, O'Bryant SE, Hall JR, Barber RC. Oxidative stress, testosterone, and cognition among Caucasian and Mexican-American men with and without $\mathrm{Al}$ zheimer's disease. J Alzheimers Dis. 2014; 40(3):563-73.

17 Carmichael O, Mungas D, Beckett L, Harvey D, Tomaszewski Farias S, Reed B, et al. MRI predictors of cognitive change in a diverse and carefully characterized elderly population. Neurobiol Aging. 2012;33(1):83-95.

18 DeCarli C, Reed BR, Jagust W, Martinez O, Ortega M, Mungas D. Brain behavior relationships among African Americans, whites, and Hispanics. Alzheimer Dis Assoc Disord. 2008;22(4):382-91.

19 Early DR, Widaman KF, Harvey D, Beckett L, Park LQ, Farias ST, et al. Demographic predictors of cognitive change in ethnically diverse older persons. Psychol Aging. 2013; 28(3):633-45.

20 Mungas D, Reed BR, Farias ST, Decarli C. Age and education effects on relationships of cognitive test scores with brain structure in demographically diverse older persons. Psychol Aging. 2009;24(1):116-28.

21 Menon C, Hall J, Hobson V, Johnson L, O'Bryant SE. Normative performance on the executive clock drawing task in a multi-ethnic bilingual cohort: a project FRONTIER study. Int J Geriatr Psychiatry. 2012;27(9):959-66.

22 O’Bryant SE, Hall JR, Cukrowicz KC, Edwards $\mathrm{M}$, Johnson LA, Lefforge $\mathrm{D}$, et al. The differential impact of depressive symptom clusters on cognition in a rural multi-ethnic cohort: a project FRONTIER study. Int J Geriatr Psychiatry. 2011;26(2):199-205. 
23 Lamar M, Wu D, Durazo-Arvizu RA, Brickman AM, Gonzalez HM, Tarraf W, et al. Cognitive associates of current and more intensive control of hypertension: findings from the Hispanic Community Health Study/Study of Latinos. Am J Hypertens. 2017;30(6):624-31.

24 Strizich G, Kaplan RC, González HM, Daviglus ML, Giachello AL, Teng Y, et al. Glycemic control, cognitive function, and family support among middle-aged and older Hispanics with diabetes: the Hispanic Community Health Study/Study of Latinos. Diabetes Res Clin Pract. 2016;117:64-73.

25 Al Hazzouri AZ, Haan MN, Galea S, Aiello AE. Life-course exposure to early socioeconomic environment, education in relation to late-life cognitive function among older Mexicans and Mexican Americans. J Aging Health. 2011;23(7):1027-49.

26 Zeki Al Hazzouri A, Haan MN, Neuhaus JM, Pletcher M, Peralta CA, López L, et al. Cardiovascular risk score, cognitive decline, and dementia in older Mexican Americans: the role of sex and education. J Am Heart Assoc. 2013; 2(2):e004978.

27 Mungas D, Early DR, Glymour MM, Zeki Al Hazzouri A, Haan MN. Education, bilingualism, and cognitive trajectories: Sacramento Area Latino Aging Study (SALSA). Neuropsychology. 2018;32(1):77-88.

28 Alfaro-Acha A, Al Snih S, Raji MA, Kuo YF, Markides KS, Ottenbacher KJ. Handgrip strength and cognitive decline in older Mexican Americans. J Gerontol A Biol Sci Med Sci. 2006;61(8):859-65.

29 Alfaro-Acha A, Al Snih S, Raji MA, Markides KS, Ottenbacher KJ. Does 8-foot walk time predict cognitive decline in older Mexicans Americans? J Am Geriatr Soc. 2007;55(2): $245-51$.

30 Downer B, Raji MA, Markides KS. Relationship between metabolic and vascular conditions and cognitive decline among older Mexican Americans. Int J Geriatr Psychiatry. 2016;31(3):213-21.

31 Howrey BT, Raji MA, Masel MM, Peek MK. Stability in cognitive function over 18 years: prevalence and predictors among older Mexican Americans. Curr Alzheimer Res. 2015; 12(7):614-21.

32 Bilbrey AC, Humber MB, Plowey ED, Garcia I, Chennapragada L, Desai K, et al. The impact of Latino values and cultural beliefs on brain donation: results of a pilot study to develop culturally appropriate materials and methods to increase rates of brain donation in this under-studied patient group. Clin Gerontol. 2018;41(3):237-48.

33 Boise L, Hinton L, Rosen HJ, Ruhl M. Will my soul go to heaven if they take my brain? beliefs and worries about brain donation among four ethnic groups. Gerontologist. 2017;57(4): 719-34.

34 Bennett DA, Schneider JA, Arvanitakis Z, Wilson RS. Overview and findings from the religious orders study. Curr Alzheimer Res. 2012;9(6):628-45.
35 Bennett DA, Schneider JA, Buchman AS, Barnes LL, Boyle PA, Wilson RS. Overview and findings from the rush Memory and $\mathrm{Ag}$ ing Project. Curr Alzheimer Res. 2012;9(6): 646-63.

36 Barnes LL, Leurgans S, Aggarwal NT, Shah RC, Arvanitakis Z, James BD, et al. Mixed pathology is more likely in black than white decedents with Alzheimer dementia. Neurology. 2015;85(6):528-34.

37 Barnes LL, Shah RC, Aggarwal NT, Bennett DA, Schneider JA. The Minority Aging Research Study: ongoing efforts to obtain brain donation in African Americans without dementia. Curr Alzheimer Res. 2012;9(6):734-45.

38 Acosta-Córdova JM. The Latino neighborhoods report: issues and prospects for Chicago. Institute for Research on Race and Public Policy \& Great Cities Institute; 2017.

39 Costa PT, McCrae RR. Revised NEO personality inventory (NEO-PI-R) and NEO fivefactor inventory (NEO-FFI) professional manual. Odessa, FL: Psychological Assessment Resources, Inc.; 1992.

40 Kohout FJ, Berkman LF, Evans DA, CornoniHuntley J. Two shorter forms of the CES-D (Center for Epidemiological Studies Depression) depression symptoms index. J Aging Health. 1993;5(2):179-93.

41 Morris JC, Heyman A, Mohs RC, Hughes JP, van Belle G, Fillenbaum G, et al. The Consortium to Establish a Registry for Alzheimer's Disease (CERAD). Part I. Clinical and neuropsychological assessment of Alzheimer's disease. Neurology. 1989;39(9):1159-65.

42 Shults CW. Effect of selegiline (deprenyl) on the progression of disability in early Parkinson's disease. Parkinson Study Group. Acta Neurol Scand Suppl. 1993;146(20):36-42.

43 Silverman JM, Raiford K, Edland S, Fillenbaum G, Morris JC, Clark CM, et al. The Consortium to Establish a Registry for Alzheimer's Disease (CERAD). Part VI. Family history assessment: a multicenter study of first-degree relatives of Alzheimer's disease probands and nondemented spouse controls. Neurology. 1994;44(7):1253-9.

44 Arvanitakis Z, Grodstein F, Bienias JL, Schneider JA, Wilson RS, Kelly JF, et al. Relation of NSAIDs to incident $A D$, change in cognitive function, and $\mathrm{AD}$ pathology. Neurology. 2008;70(23):2219-25.

45 Arvanitakis Z, Schneider JA, Wilson RS, Bienias JL, Kelly JF, Evans DA, et al. Statins, incident Alzheimer disease, change in cognitive function, and neuropathology. Neurology. 2008;70(19 Pt 2):1795-802.

46 DeVito CA, Aldridge GW, Wilson A, Vidis JS, Goldberg T, Dickson WM, et al. Framework and development of a comprehensive drug product coding system. Contemp Pharm Pract. 1979;2(2):62-5.

47 Featherman DL, Hauser RM. The measurement of occupation in social surveys. In: Hauser RM, Featherman DL, editors. The process of stratification. Orlando: Academic Press; 1977. p. 51-80.
48 Ruggles S, Alexander JT, Genadek K, Goeken $\mathrm{R}$, Schroeder M, Sobek M, et al. Integrated public use microdata series, version 3.0. Minneapolis: University of Minnesota; 2012.

49 Wilson RS, Scherr PA, Hoganson G, Bienias JL, Evans DA, Bennett DA. Early life socioeconomic status and late life risk of Alzheimer's disease. Neuroepidemiology. 2005;25(1):8-14.

50 Buchman AS, Boyle PA, Wilson RS, Bienias JL, Bennett DA. Physical activity and motor decline in older persons. Muscle Nerve. 2007; 35(3):354-62.

51 Buchman AS, Boyle PA, Wilson RS, Fleischman DA, Leurgans S, Bennett DA. Association between late-life social activity and motor decline in older adults. Arch Intern Med. 2009;169(12):1139-46.

52 Cornoni-Huntley J, Brock DB, Ostfeld AM, Taylor JO, Wallace RB, editors. Established populations for epidemiologic studies of the elderly resource data book. Washington, D.C.: US Government Printing Office; 1986.

53 Dams-O'Connor K, Cantor JB, Brown M, Dijkers MP, Spielman LA, Gordon WA. Screening for traumatic brain injury: findings and public health implications. J Head Trauma Rehabil. 2014;29(6):479-89.

54 Katz S, Akpom CA. A measure of primary sociobiological functions. Int $J$ Health Serv. 1976;6(3):493-508.

55 Lawton MP, Brody EM. Assessment of older people: self-maintaining and instrumental activities of daily living. Gerontologist. 1969;9(3):179-86.

56 Spector WD, Fleishman JA. Combining activities of daily living with instrumental activities of daily living to measure functional disability. J Gerontol B Psychol Sci Soc Sci. 1998;53(1):S46-57.

57 Nagi SZ. An epidemiology of disability among adults in the United States. Milbank Mem Fund Q Health Soc. 1976;54(4):439-67.

58 Rosow I, Breslau N. A Guttman health scale for the aged. J Gerontol. 1966;21(4):556-9.

59 Foulkes MA, Wolf PA, Price TR, Mohr JP, Hier DB. The Stroke Data Bank: design, methods, and baseline characteristics. Stroke. 1988;19(5):547-54.

60 Goldstein LB, Bertels C, Davis JN. Interrater reliability of the NIH stroke scale. Arch Neurol. 1989;46(6):660-2.

61 Bennett DA, Shannon KM, Beckett LA, Goetz CG, Wilson RS. Metric properties of nurses' ratings of parkinsonian signs with a modified Unified Parkinson's Disease Rating Scale. Neurology. 1997;49(6):1580-7.

62 Bennett DA, Shannon KM, Beckett LA, Wilson RS. Dimensionality of parkinsonian signs in aging and Alzheimer's disease. J Gerontol A Biol Sci Med Sci. 1999;54(4):M191-6.

63 Cohen NJ, Ryan J, Hunt C, Romine L, Wszalek T, Nash C. Hippocampal system and declarative (relational) memory: summarizing the data from functional neuroimaging studies. Hippocampus. 1999;9(1):83-98.

64 Gabrieli JD. Cognitive neuroscience of human memory. Annu Rev Psychol. 1998;49: 87-115. 
65 Squire LR, Zola SM. Structure and function of declarative and nondeclarative memory systems. Proc Natl Acad Sci U S A. 1996;93(24): 13515-22.

66 Albert M, Smith LA, Scherr PA, Taylor JO, Evans DA, Funkenstein HH. Use of brief cognitive tests to identify individuals in the community with clinically diagnosed Alzheimer's disease. Int J Neurosci. 1991;57(3-4):167-78.

67 Benton AL, Varney NR, Hamsher KD. Visuospatial judgment. A clinical test. Arch Neurol. 1978;35(6):364-7.

68 Cooper JA, Sagar HJ. Incidental and intentional recall in Parkinson's disease: an account based on diminished attentional resources. J Clin Exp Neuropsychol. 1993;15(5): 713-31.

69 Ekstrom RB, French JW, Harman HH, Dermen D. Manual for kit of factor-referenced cognitive tests. Princeton: Educational Testing Service; 1976.

70 Goodglass H, Kaplan E. The assessment of aphasia and related disorders. Philadelphia: Lea \& Febiger; 1972.

71 Raven JC, Court JH, Raven J. Standard progressive matrices-1992 edition. Raven manual: section 3. Oxford: Oxford Psychologists Press; 1992.

72 Smith A. Symbol Digit Modalities test manual-revised. Los Angeles: Western Psychological Services; 1982.

73 Trenerry MR, Crosson B, Debae J, Leber WR. The Stroop neuropsychological screening test. Odessa, FL: Psychological Assessment Resources; 1989.

74 Wechsler D. Wechsler memory scale-revised manual. New York: Psychological Corporation; 1987.

75 Welsh KA, Butters N, Hughes JP, Mohs RC, Heyman A. Detection and staging of dementia in Alzheimer's disease. Use of the neuropsychological measures developed for the Consortium to Establish a Registry for Alzheimer's disease. Arch Neurol. 1992;49(5): 448-52.

76 Willshire D, Kinsella G, Prior M. Estimating WAIS-R IQ from the National Adult Reading Test: a cross-validation. J Clin Exp Neuropsychol. 1991;13(2):204-16.

77 Marquine MJ, Segawa E, Wilson RS, Bennett DA, Barnes LL. Association between cognitive activity and cognitive function in older Hispanics. J Int Neuropsychol Soc. 2012; 18(6):1041-51.

78 Wilson RS, Capuano AW, Marquez DX, Amofa P, Barnes LL, Bennett DA. Change in cognitive abilities in older Latinos. J Int Neuropsychol Soc. 2016;22(1):58-65.

79 Folstein MF, Folstein SE, McHugh PR. "Minimental state". A practical method for grading the cognitive state of patients for the clinician. J Psychiatr Res. 1975;12(3):189-98.

80 Krueger KR, Wilson RS, Bennett DA, Aggarwal NT. A battery of tests for assessing cognitive function in older Latino persons. Alzheimer Dis Assoc Disord. 2009;23(4):384-8.
81 Wilson R, Barnes L, Bennett D. Assessment of lifetime participation in cognitively stimulating activities. J Clin Exp Neuropsychol. 2003; 25(5):634-42.

82 Wilson RS, Aggarwal NT, Barnes LL, Mendes de Leon CF, Hebert LE, Evans DA. Cognitive decline in incident Alzheimer disease in a community population. Neurology. 2010; 74(12):951-5.

83 Wilson RS, Barnes LL, Krueger KR, Hoganson G, Bienias JL, Bennett DA. Early and late life cognitive activity and cognitive systems in old age. J Int Neuropsychol Soc. 2005;11(4): 400-7.

84 Wilson RS, Beckett LA, Barnes LL, Schneider JA, Bach J, Evans DA, et al. Individual differences in rates of change in cognitive abilities of older persons. Psychol Aging. 2002;17(2): 179-93.

85 Buchman AS, Wilson RS, Leurgans SE, Bennett DA, Barnes LL. Change in motor function and adverse health outcomes in older AfricanAmericans. Exp Gerontol. 2015;70:71-7.

86 Buchman AS, Leurgans SE, Boyle PA, Schneider JA, Arnold SE, Bennett DA. Combinations of motor measures more strongly predict adverse health outcomes in old age: the rush memory and aging project, a community-based cohort study. BMC Med. 2011;9:42.

87 Bennett DA, Schneider JA, Aggarwal NT, Arvanitakis Z, Shah RC, Kelly JF, et al. Decision rules guiding the clinical diagnosis of $\mathrm{Alz}$ heimer's disease in two community-based cohort studies compared to standard practice in a clinic-based cohort study. Neuroepidemiology. 2006;27(3):169-76.

88 Lesné SE, Sherman MA, Grant M, Kuskowski M, Schneider JA, Bennett DA, et al. Brain amyloid- $\beta$ oligomers in ageing and Alzheimer's disease. Brain. 2013;136(Pt 5):1383-98.

89 Bennett DA, Wilson RS, Schneider JA, Evans DA, Beckett LA, Aggarwal NT, et al. Natural history of mild cognitive impairment in older persons. Neurology. 2002;59(2):198-205.

90 Adams HP Jr, Biller J. Classification of subtypes of ischemic stroke: history of the trial of org 10172 in acute stroke treatment classification. Stroke. 2015;46(5):e114-7.

91 Román GC, Tatemichi TK, Erkinjuntti T, Cummings JL, Masdeu JC, Garcia JH, et al. Vascular dementia: diagnostic criteria for research studies. Report of the NINDS-AIREN International Workshop. Neurology. 1993; 43(2):250-60.

92 Langston JW, Widner H, Goetz CG, Brooks D, Fahn S, Freeman T, et al. Core assessment program for intracerebral transplantations (CAPIT). Mov Disord. 1992;7(1):2-13.

93 Boyle PA, Wilson RS, Yu L, Barr AM, Honer WG, Schneider JA, et al. Much of late life cognitive decline is not due to common neurodegenerative pathologies. Ann Neurol. 2013; 74(3):478-89.

94 Marín G, Sabogal F, Marin BV, Otero-Sabogal R, Pérez-Stable EJ. Development of a short acculturation scale for Hispanics. Hispanic J Behav Sci. 1987;9(2):183-205.
95 Sabogal F, Marín G, Otero-Sabogal R, Marín BV, Perez-Stable EJ. Hispanic familism and acculturation: what changes and what doesn't? Hispanic J Behav Sci. 1987;9(4): 397-412.

96 Daviglus ML, Talavera GA, Avilés-Santa ML, Allison M, Cai J, Criqui MH, et al. Prevalence of major cardiovascular risk factors and cardiovascular diseases among Hispanic/Latino individuals of diverse backgrounds in the United States. JAMA. 2012;308(17): 1775-84.

97 Lora CM, Ricardo AC, Chen J, Cai J, Flessner $\mathrm{M}$, Moncrieft A, et al. Acculturation and chronic kidney disease in the Hispanic community health study/study of Latinos (HCHS/SOL). Prev Med Rep. 2018;10:28591.

98 Hooker K, Phibbs S, Irvin VL, Mendez-Luck CA, Doan LN, Li T, et al. Depression among older adults in the United States by disaggregated race and ethnicity. Gerontologist. 2019;59:886-91.

99 Gallagher D, Kiss A, Lanctot K, Herrmann N. Depression and risk of Alzheimer dementia: a longitudinal analysis to determine predictors of increased risk among older adults with depression. Am J Geriatr Psychiatry. 2018;26(8):819-27.

100 Arnold SE, Xie SX, Leung YY, Wang LS, Kling MA, Han X, et al. Plasma biomarkers of depressive symptoms in older adults. Transl Psychiatry. 2012;2:e65.

101 Arvanitakis Z, Brey RL, Rand JH, Schneider JA, Capuano AW, Yu L, et al. Relation of antiphospholipid antibodies to postmortem brain infarcts in older people. Circulation. 2015;131(2):182-9.

102 Bennett DA, Yu L, De Jager PL. Building a pipeline to discover and validate novel therapeutic targets and lead compounds for $\mathrm{Al}$ zheimer's disease. Biochem Pharmacol. 2014;88(4):617-30.

103 De Jager PL, Srivastava G, Lunnon K, Burgess J, Schalkwyk LC, Yu L, et al. Alzheimer's disease: early alterations in brain DNA methylation at ANK1, BIN1, RHBDF2 and other loci. Nat Neurosci. 2014;17(9):1156-63.

104 Lu T, Aron L, Zullo J, Pan Y, Kim H, Chen $\mathrm{Y}$, et al. Addendum: REST and stress resistance in ageing and Alzheimer's disease. Nature. 2014;540(7633):470-54.

105 Mufson EJ, Leurgans S. Inability of plasma and urine F2A-isoprostane levels to differentiate mild cognitive impairment from $\mathrm{Al}$ zheimer's disease. Neurodegener Dis. 2010, 7(1-3):139-42.

106 Raj T, Shulman JM, Keenan BT, Chibnik LB, Evans DA, Bennett DA, et al. Alzheimer disease susceptibility loci: evidence for a protein network under natural selection. Am J Hum Genet. 2012;90(4):720-6.

107 Shulman JM, Chen K, Keenan BT, Chibnik LB, Fleisher A, Thiyyagura P, et al. Genetic susceptibility for Alzheimer disease neuritic plaque pathology. JAMA Neurol. 2013; 70(9):1150-7. 